\title{
PHENO-MORPHOLOGICAL AND AGRONOMIC DIVERSITY IN A COLLECTION OF WILD AND DOMESTICATED SPECIES OF THE GENUS LUPINUS
}

\author{
Dariusz ZALEWSKI, Renata GALEK*, Bartosz KOZAK, Ewa SAWICKA-SIENKIEWICZ \\ Wroclaw University of Environmental and Life Sciences, Plant Breeding and Seed Production, \\ Department of Genetics, Wroclaw, POLAND \\ Corresponding author: renata.galek@up.wroc.pl
}

Received: 27.10 .2014

\begin{abstract}
The aim of this study was evaluated variability in collection of 20 genotypes represented eight domesticated and wild species of genus Lupinus. Analyses were made using multi-dimensional assessment based on twenty simultaneously considered characters from three years fields experiment. The cluster analysis (CA) and principal component analysis (PCA) were performed for illustrated diversity among investigated genotypes. The first three principal components contributed for $\mathbf{7 5 . 8 \%}$ of the overall multi-trait variability in the means of all analyzed characters. The first principal component was found to account for $38.4 \%$ of the variability. The phenological phases and the height of a plant had the greatest contribution to this particular component. The second principal component accounted for $\mathbf{2 3 . 3} \%$ of the diversity regarding the number of pods from a lateral stem and emergence. On the other hand, the number of pods from the main stem and 1000 -seed weight constituted traits the strongest linked with the third principal component, which accounted for $14.1 \%$ of the diversity. The obtained results will be helpful to define a strategy in the future lupin breeding programs.
\end{abstract}

Keywords: pheno-morphological traits, agronomic traits, cluster analysis, genus Lupinus, principal component analysis

\section{INTRODUCTION}

Genus Lupinus is a large group of interesting and usefulness species. Lupins are an excellent source of protein and oil, and therefore they have been applicate in animal nutrition and the human diet (as a supplement to low-calories food especially for diabetics). Furthermore, alkaloid compounds, mostly quinolizidine group contained in the lupine seeds may be useful for the manufacture of blood pressure lowering drugs, and analgesics (Heistinger and Pistrick, 2007; Fychan et. al., 2008; Sipsas, 2008; Sweetingham and Kingwell, 2008).

Discovering on the "new" lupin is associated with the current global trends in agronomical practices, aimed towards promoting organic farming, designed to protect the environment. Lupin belongs to desirable elements in cropping system, especially as a plant rotary with cereals and oilseeds, due to the beneficial effect on soil fertility and increasing plant health. Lupins have a significant impact on the growth yield of succeeding plant crops (Evans et al., 2001).

The extraordinary adaptability value of lupins species was resulted in spreading them on several continents. The genus Lupinus has two centers of natural distribution. One of them is situated in the Mediterranean region, which is the so-called Old World, with ecological niches reaching as far as Central Africa. The other covers the western coast of Americas, stretching through Alaska (in the north) up to Argentina, with a large subcentre in Brazil the so-called New World. Although New World lupins are represented by about 300 species only one - Lupinus mutabilis was domesticated (Römer et al., 1999). In the region of the Mediterranean Sea basin and Africa there are 13 annual species, which have been divided into groups and taxonomic sections based on serological reactions of their storage proteins, morphological similarity and results of experiments aimed at acquisition of interspecific hybrids. With regard to the built of the seed coat, two groups have been distinguished, i.e. smooth- and roughseeded species. The group of smooth-seeded lupins is formed by the following sections: Albus, Luteus, Angustifolius and Micranthus, whereas in the roughseeded there are Pilosus, Atlanticus, Princei and Somaliensis. The Mediterranean region constitutes the natural distribution area of three cultivated species with smooth-seeded - L. albus, L. luteus, L. angustifolius (Gladstones et al., 1998). 
The lupin breeding progress is caused by crossing varieties or breeding lines, spontaneous and induced mutants and by carrying out the selection pressure (Buirchel, 1994). Opportunities to increase genetic variation using interspecific hybrids in the genus Lupinus are difficult because of differences in the number of chromosomes between species of crops belonging to different taxonomic sections and developed cytogenetic barriers during of evolution, although possible (Clements et al., 2008; Sawicka-Sienkiewicz et al., 2008). In view of this situation, there is need for conducting a separate breeding of each cultivated species of lupine (white, yellow, narrow-leafed and Andean lupin). In order to practical use of natural and induced variability and increase the efficiency of breeding programs it is necessary to create an appropriate genetic base and it is very important to know the range of traits variation in specific climatic conditions.

The purpose of the undertaken investigations was to arrive at multi-dimensional assessment of diversity of the lupin collection gathered at the Department of Genetics, Plant Breeding and Seed Production.

\section{MATERIALS AND METHODS}

The collection consisted of specimens that represented eight species from the genus Lupinus: Lupinus albus L. (cv. Butan), L. angustifolius L. (cvs. Elf, Emir, Graf), L. mutabilis (cvs. Potosi, selected lines from populations POP.15, XM.5, LM.34), L. hispanicus subsp. hispanicus (Plant Introduction No. - PI 385134), L. pilosus (PI 11424, 491183, 249758), L. palaestinus (PI 15616), L. cosentinii (PI 32535, 32533, 32534, 32530) and $L$. atlanticus (PI 384613, 386413). Three years' field experiments (2003-2005) were established by the method of randomized blocks and carried out in three replications. Seeds of twenty genotypes were sown at the spacing of 10 $\mathrm{cm} \times 20 \mathrm{~cm}$, on experimental plots covering $1 \mathrm{~m}^{2}$. The measurements were taken from ten randomly chosen plants growing in a given plot. The characters of subsequent plants were recorded, including morphological and related to the yield structure (Table 1) were evaluated.

Table 1. Eigenvectors of the twenty pheno-morphological and agronomic traits for first third principal components (PCs) in 20 genotypes of genus Lupinus

\begin{tabular}{|c|c|c|c|}
\hline & PC1 $(38.4 \%)$ & PC2 $(23.3 \%)$ & PC3 (14.1\%) \\
\hline Traits & & Eigen vector & \\
\hline Height of plant $(\mathrm{cm})$ & -0.75 & 0.50 & -0.02 \\
\hline Height of main stem $(\mathrm{cm})$ & -0.70 & 0.31 & -0.16 \\
\hline Lateral branches no. & -0.34 & -0.67 & 0.24 \\
\hline Inflorescence length of main stem $(\mathrm{cm})$ & -0.39 & 0.68 & -0.47 \\
\hline Pods no. on main stem & -0.06 & 0.30 & -0.87 \\
\hline Inflorescence length of lateral branches $(\mathrm{cm})$ & -0.56 & 0.59 & -0.12 \\
\hline Pods no. on lateral branches & -0.12 & -0.45 & -0.46 \\
\hline Pods no. from lateral branch & -0.43 & -0.81 & -0.01 \\
\hline Pods no. per plant & -0.48 & -0.66 & -0.48 \\
\hline Harvest index - main stem $(\%)$ & 0.56 & -0.18 & -0.48 \\
\hline Harvest index - lateral branch $(\%)$ & 0.54 & -0.65 & -0.04 \\
\hline Weight of 1000 seeds $(\mathrm{g})$ & 0.18 & 0.59 & 0.70 \\
\hline Emergence & -0.31 & 0.70 & -0.10 \\
\hline 1st pair of leaves & -0.68 & -0.18 & -0.49 \\
\hline Budding of the main stem & -0.68 & -0.40 & 0.31 \\
\hline Flowering on the main stem & -0.88 & -0.31 & 0.16 \\
\hline Flowering on lateral branches & -0.93 & -0.09 & 0.07 \\
\hline Pods setting on the main stem & -0.90 & -0.26 & 0.16 \\
\hline Pods setting on lateral branches & -0.91 & 0.09 & -0.07 \\
\hline Vegetation period & -0.81 & 0.07 & 0.42 \\
\hline
\end{tabular}

Note. Values in bold indicate values $\geq 0.7$ for each principal components.

Means of each character were standardized prior to analysis in order to avoid the effect due to differences in scale. The standardization of mean was made to provide a multivariate analysis.

A multivariate analysis was performed to calculate the average Euclidian distances between each pair of accessions, and then compiled into a matrix. The data from this matrix were next used both for Cluster Analysis (CA) and Principal Component Analysis (PCA). In the $\mathrm{CA}$, the accessions were clustered into hierarchical groups represented in a dendrogram according to the Unweighed
Pair Group Method using Arithmetic Averages (UPGMA). In the PCA, a multidimensional data set of 20 characters, 20 accessions, were analyzed. According to Kaiser's criterion (Kaiser, 1960), only those principal components analysis (PCA) that showed the eigen value $>=1$ were taken into account. Correlation coefficients were calculated between characters, compiled into a matrix and submitted to a and PCA. The calculations for CA were made with the application of the STATISTICA 10.0 software. For division of the obtained clusters, Grabiński's criterion (1992) was applied, which assumes 
"cutting off" of a dendrogram at the point where the quotient of neighbouring distances represents the highest value. Graphically, location of particular genotypes was shown in the space of the first three principal components with the use of the NTsys PC 2.21.

\section{RESULTS AND DISCUSSION}

The first three principal components accounted for $75.8 \%$ of the overall multi-trait variability in the means of all characters analyzed in twenty genotypes under evaluation. The first principal component was found to account for $38.4 \%$ of the variability. The phenological phases and the height of a plant had the greatest contribution to this particular component. The second principal component accounted for $23.3 \%$ of the diversity regarding the number of pods from a lateral stem and emergence. On the other hand, the number of pods from the main stem and 1000-seed weight constituted traits the strongest linked with the third principal component, which accounted for $14.1 \%$ of the diversity (Table 1).

The performed analysis allowed to divide the studied genotypes into six clusters using $\mathrm{CA}$ and five cluster based on PCA (Fig. 1, 2). L. hispanicus ssp. hispanicus was the species that was clearly distinguishable from the others and formed separately cluster I based on CA and PCA. This is an effect of pressure selection in different than in other species climatic and soil conditions selection. This species, however, cannot be directly used as initial material for breeding due to a number of disadvantageous properties, i.e. too long the vegetation period, production of a large number of lateral branches and too low index of harvest from the main stem and from the lateral ones (Table 2). The three studied cultivars of the narrow-leaved lupin fell within one group - cluster IV (Fig. 1, 2; Table 1). L. angustifolius is the widest cultivated species from the genus Lupinus. This group of lupins was characterized by an array of favorable traits, short vegetation period and a reduced number of lateral branches in particular. Its failure, however - as in the majority of lupins - are abortion of flowers and juvenile pods, which negatively affected the index of harvest from the main and lateral branches (Table 2). Genotypes representing L. cosentinii grouped in cluster V. They characterized by lower abscission of flowers and pods from the main stem and the lateral branches (Table 2). Besides, they didn't produce numerous lateral branches, were short. Investigated genotypes of $L$. cosentinii could be used in breeding aimed at improvement of yield structure traits and shorted vegetation period.

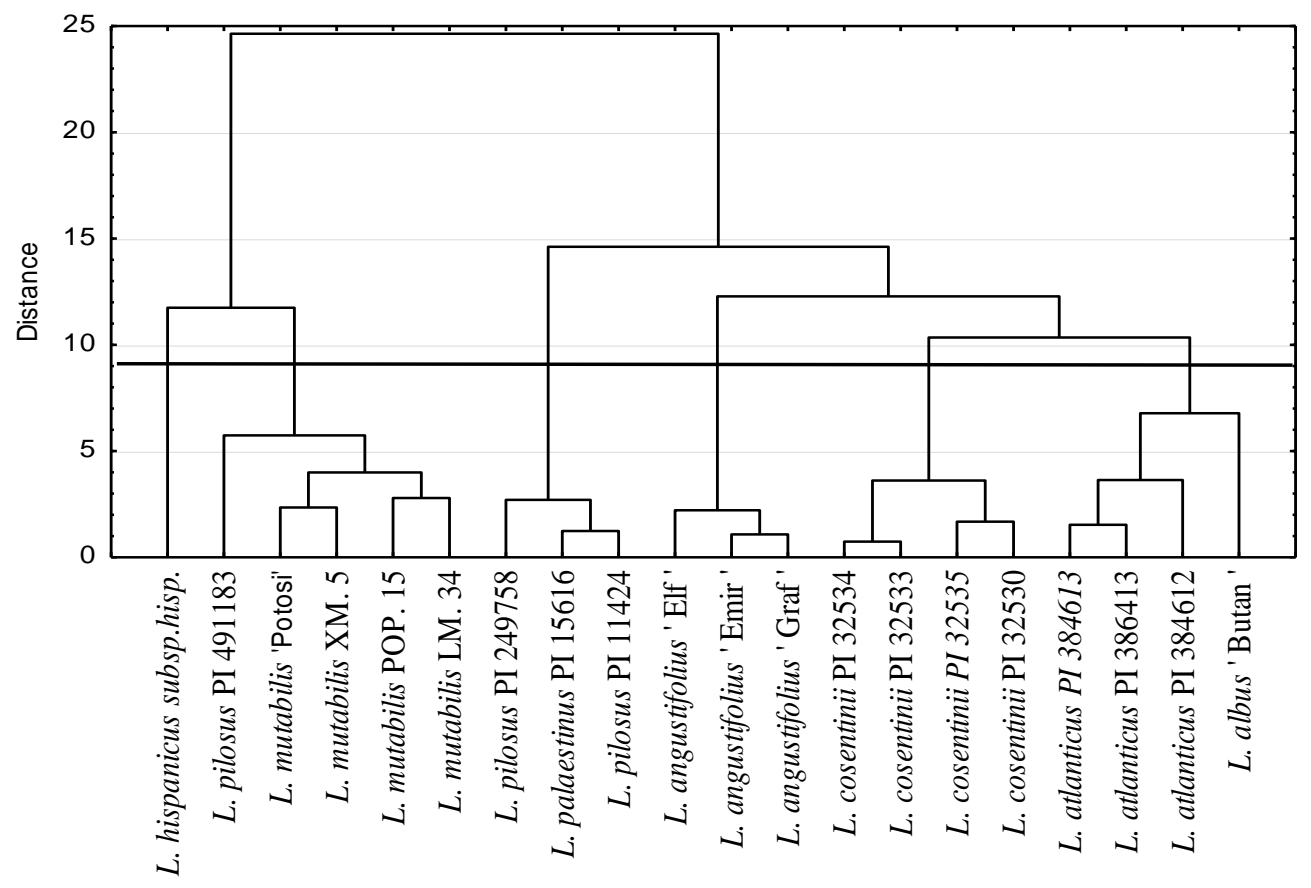

Figure 1. Dendrogram based on twenty analyzed traits in collection of Lupinus genotypes 


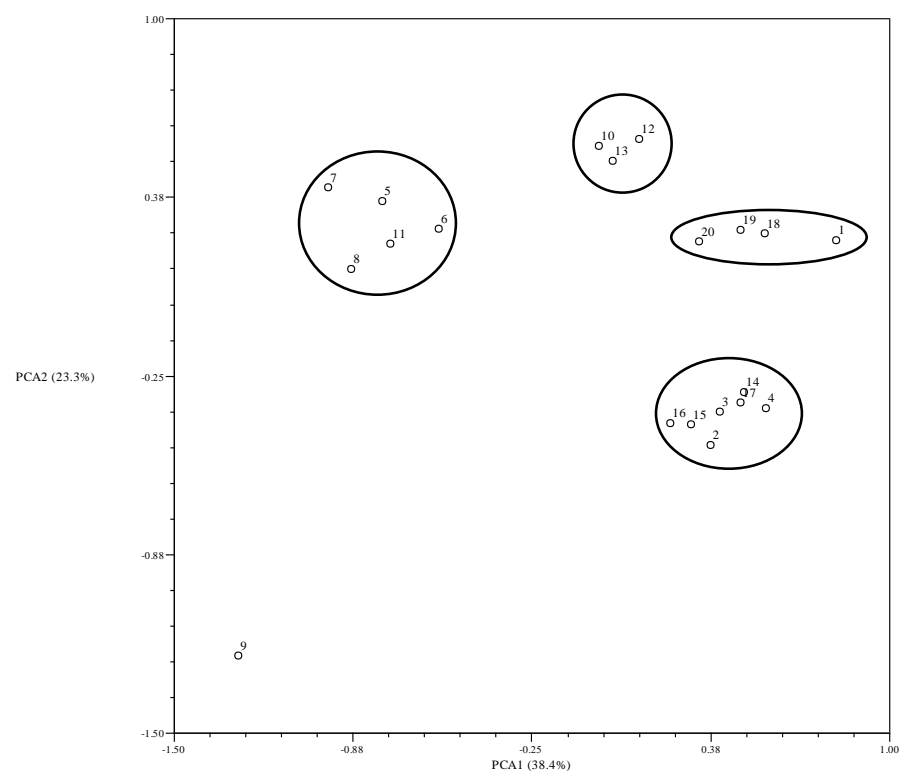

Figure 2. PCA biplot of 20 traits in collection Lupinus genotypes

1 - L. albus 'Butan'; 2 - L. angustifolius 'Graf '; 3 - L. angustifolius 'Emir'; 4 - L. angustifolius 'Elf'; 5 - L. mutabilis LM. 34; 6 - L. mutabilis XM. 5; 7 - L. mutabilis POP. 15; 8 -L. mutabilis 'Potossi '; 9 - L. hispanicus subsp.hisp.; 10 - L. pilosus PI 11424 ; 11 - L. pilosus PI 491183; 12 - L. pilosus PI 249758; 13 - L. palaestinus PI 15616; 14 - L. cosentinii PI 32530; 15 - L. cosentinii PI 32533; 16 - L. cosentinii PI 32534; 17 - L. cosentinii PI 32535; 18 - L. atlanticus PI 384612; 19 - L. atlanticus PI 386413; 20 - L. atlanticus PI 384613

Table 2. Mean values of pheno-morphological and agronomical characters in the groups obtained by clusters analysis

\begin{tabular}{|c|c|c|c|c|c|c|c|}
\hline \multirow[b]{3}{*}{ Traits } & \multicolumn{7}{|c|}{ Mean } \\
\hline & \multicolumn{6}{|c|}{ Clusters* } & \multirow[b]{2}{*}{ Mean } \\
\hline & I & II & III & IV & V & VI & \\
\hline Height of plant $(\mathrm{cm})$ & 49.4 & 75.2 & 63.0 & 49.1 & 38.0 & 40.6 & 52.6 \\
\hline Height of main stem $(\mathrm{cm})$ & 57.1 & 86.4 & 69.0 & 55.3 & 63.9 & 45.6 & 62.9 \\
\hline Lateral branches no. & 6.6 & 3.5 & 3.2 & 5.1 & 3.0 & 2.5 & 4.0 \\
\hline Inflorescence length of main stem $(\mathrm{cm})$ & 9.8 & 24.0 & 18.2 & 17.6 & 13.6 & 17.4 & 16.8 \\
\hline Pods no. on main stem & 6.9 & 13.8 & 7.6 & 8.6 & 11.7 & 13.3 & 10.3 \\
\hline Inflorescence length of lateral branches $(\mathrm{cm})$ & 5.9 & 12.0 & 10.2 & 7.7 & 5.8 & 7.4 & 8.2 \\
\hline Pods no. on lateral branches & 5.8 & 5.4 & 4.1 & 4.4 & 6.7 & 4.3 & 5.1 \\
\hline Pods no. from lateral branch & 36.9 & 19.8 & 14.1 & 23.3 & 20.3 & 10.6 & 20.8 \\
\hline Pods no. per plant & 43.9 & 33.5 & 21.9 & 31.8 & 31.8 & 23.8 & 31.1 \\
\hline Harvest index - main stem $(\%)$ & 40.2 & 36.5 & 33.3 & 40.7 & 54.4 & 56.8 & 43.7 \\
\hline Harvest index - lateral branch & 40.0 & 26.0 & 28.7 & 45.3 & 60.2 & 32.4 & 38.8 \\
\hline Weight of 1000 seeds $(\mathrm{g})$ & 62.8 & 186.9 & 571.3 & 148.0 & 218.8 & 252.8 & 240.1 \\
\hline Emergence & 14.0 & 17.1 & 17.1 & 12.4 & 15.7 & 17.0 & 15.6 \\
\hline 1st pair of leaves & 7.8 & 7.7 & 4.4 & 6.2 & 5.5 & 5.5 & 6.2 \\
\hline Budding of the main stem & 73.6 & 44.0 & 39.8 & 33.7 & 38.4 & 37.4 & 44.5 \\
\hline Flowering on the main stem & 81.2 & 58.7 & 48.2 & 44.3 & 46.6 & 44.5 & 53.9 \\
\hline Flowering on lateral branches & 87.3 & 71.1 & 58.6 & 48.0 & 55.6 & 53.4 & 62.3 \\
\hline Pods setting on the main stem & 89.0 & 65.0 & 52.9 & 45.9 & 50.7 & 48.2 & 58.6 \\
\hline Pods setting on lateral branches & 91.0 & 83.1 & 66.0 & 50.9 & 62.7 & 62.0 & 69.3 \\
\hline Vegetation period & 142.3 & 127.6 & 129.7 & 102.0 & 112.8 & 106.8 & 120.2 \\
\hline
\end{tabular}
*

Cluster I L. hispanicus ssp. hispanicus

Cluster II $\quad$ L.pilosus PI 491183, L.mutabilis 'Potosi', L. mutabilis POP. 15, L. mutabilis XM. 5, L.mutabilis LM. 34

Cluster III L. palaestinus PI 15616, L. pilosus PI 11424, PI 249758

Cluster IV L. angustifolius 'Elf', 'Emir', 'Graf'

Cluster V L. cosentinii PI 32535, PI 32533, PI 32534, PI 32530

Cluster VI L. atlanticus PI 384613, PI 386413, PI 384612, L. albus 'Butan' 
The similarity of the white lupin cultivar Butan to $L$. atlanticus, recorded in the case of many properties (Table 2). Genotypes form those species belonged to cluster VI (Fig. 1). This fact is interesting because of $L$. albus originates from the territories within the Mediterranean Sea basin and is commonly cultivated in many countries, whereas the wild species L. atlanticus occurs in areas at higher altitudes - in the Atlas Mountains. Species belong to cluster VI characterized by a high 1000 -seed weight, and favorable harvest index for the main stem but a less favorable index of harvest from lateral branches (Table 2). Taking into consideration their large 1000-seed weight, high index of harvest from the main stem, production of insubstantial number of lateral branches and a relatively short vegetation period, these forms are particularly promising and can find use in the pertinent research and plant breeding. Simultaneously, they did not produce biomass, plants were short, had a small number of lateral branches and matured relatively early (Table 2). All the evaluated genotypes of L. mutabilis and L. pilosus (PI 491183) were classificated in one group - cluster II (Table 2, Fig1). These genotypes were high with long inflorescences, but they did not produced a favorable number of pods and their harvest index was low. What's more their disadvantage was a long vegetation period. A similarly long vegetation period was typical of the genotypes of $L$. palaestinus as well as L. pilosus PI 249758 and PI 11424, which make cluster III (Table 2, Fig 1). The character that distinguished this group was a very high weight of 1000 seeds, a property rather unfavorable in agricultural practice. Disadvantages included also the tendency to produce a large biomass and a low harvest index.

When attempting to obtain new varieties, it is advisable to conduct a comprehensive assessment of the initial material. Breeders verify their materials based on evaluation of quantitative or qualitative traits. For evaluation of breeding material various statistical methods are employed - both uni- and multi-dimensional ones (Ghafoor and Arshad, 2008; Galek, 2010; Ilker et al., 2009; Mitrović et al., 2012).

Since the environmental impact is of high importance in the evaluation of plants' phenotype, it is justifiable when the genotype-environment interaction has been found significant - to perform analyses not only of the averages for several years but also of the results for particular years of research separately. Many authors studied two-year or three-year results for each year separately in the case of such species as the mungo bean or alfalfa (Ghafoor et al., 2002; Ghafoor and Ahmad, 2003; Ghafoor and Arshad, 2008) and thus they did not carry out analyses of the data averaged for several years. However, Ghafoor et al. (2008) evaluated a very large number of mungo bean genotypes (484) based on the annual means. The research by Di Giorgio et al. (2009) also pertained to the results of annuals but samples were taken from 36 locations of natural populations of the Scorpiurus muricatus. In our study we used analyses based on means from three years period.
Application in our study of principal component and cluster analyses allows to specify which attributes among all the 20 analyzed are of importance in the overall variability. It also gives us the ability to designate groups of similar genotypes for all the characteristics and to determine which genotypes are distinguishable in terms of several features together. This allows to chosen an appropriate strategy for the breeding program.

The multidimensional analysis of principal components for wild and domesticated species of the lupin, which has for the first time been undertaken, made it possible to define which characters are of utmost importance in shaping the observed diversity. The simultaneously applied cluster analysis enabled to group the genotypes in respect of their similarity based on twenty traits in total, an outcome which can be very helpful in selection-breeding practice.

\section{LITERATURE CITED}

Buirchell, B.J. 1994. Domestication and potential of the roughseeded lupins. In: Neves-Martins, Beirão da Costa ML editors. Proceedings of the $7^{\text {th }}$ International Lupin Conference Advances in Lupin Research, 18-23 April 1993; Evora, Portugal: International Lupin Association, pp.19-24.

Clements, J., L. Prilyuk, J. Quealy and G. Francis. 2008. Interspecific crossing among the New World lupin species for Lupinus mutabilis crop improvement. In: Palta JA, Berger JD, editors. Proceedings of the $12^{\text {th }}$ International Lupin Conference Lupin for Health and Wealth, 14-18 September 2008; Fremantle, Western Australia: International Lupin Association, pp. 324-327.

Di Giorgio, G., D. Graziano, P. Ruisi, G. Amato and D. Giambalvo. 2009. Pheno-morphological and agronomic diversity among Scorpiurus muricatus (Fabaceae) natural populations collected in Sicily. J Agric Science 147:411422.

Evans, J., A.M., McNeill, M.J., Unkovich, N.A., Fettell and D.P. Heenan. 2001. Net nitrogen balances for cool-season grain legume crops and contributions to wheat nitrogen uptake: a review' Australian J. of Experimental Agriculture 41:347-359.

Fychan, R., C.L, Marley., G.G., Lewis, D.R.W., Davies, V.J., Theobald, R., Jones and M.T. Abberton. 2008. Effects of feeding concentrate diets containing narrow-leaf lupin, yellow lupin or soya when compared with a control diet on the productivity of finishing lambs.In: Palta J.A., and Berger JD, editors. Proceedings of the $12^{\text {th }}$ International Lupin Conference Lupin for Health and Wealth, 14-18 September 2008; Fremantle, Western Australia: International Lupin Association, pp.127-131.

Galek R. 2010. Studies on the variability of some morphological and functional characters of Lupinus with particular consideration intra and interspecific hybrids. Dissertation, University of Environmental and Life Sciences Poland

Ghafoor, A., and Z. Ahmad. 2003. Exploitation of Vigna mungo (L.) Hepper germplasm using multivariate analysis based on agronomic traits. Pak. J. Bot. 35(2):187-196.

Ghafoor, A., Z., Ahmad, A.S., Quereshi, and M. Bashir. 2002. Genetic relationship in Vigna mungo (L.) Hepper and V. variata (L.) R. Wilczek based on morphological traits and SDS-PAGE. Euphytica 123:367-378.

Ghafoor, A. and M. Arshad. 2008. Multivariate analysis for quantitative traits to determine genetic diversity of 
blackgram (Vigna mungo (L.) Hepper germplasm. Pak. J. Bot. 40(6):2307-2313.

Gladstones, J.S., Atkins C.A., and J.Hamblin. 1998. Lupins as Crop Plants, Biology, Production and Utilization. 1 ed. Cambridge: CAB International

Grabiński, T. 1992. Basics quantification of the spatial variables The study spatial market consumption. 1 ed. Warsaw, Poland, PWN

Heistinger, A. and K. Pistrick. 2007. 'Altreier Kaffee': Lupinus pilosus L. cultivated as coffe substitute in Northern Italy (Alto Adige/Südtirol). Genet. Resour. Crop Evol. 54:16231630 .

Ilker, E., F., Aykut Tonk, O., Caylak, M., Tosun and I. Ozmen. 2009. Assessment of genotype $\mathrm{x}$ environment interactions for grain yield in maize hybrids using AMMI and GGE biplot analyses. Turkish J. of Field Crops 14(2):123-135.

Kaiser, H.F. 1960. The application of electronic computers to factor analysis. Educational and Psychological Measurement 20:141-151

Mitrović, B., D., Stanisavljevi, S., Treski, M., Stojaković, M. Ivanović, G., Bekevac and M. Rajković. 2012. Evaluation of experimental maize hybrids tested in multi-location trials using AMMI and GGE biplot analyses. Turkish J. of Field Crops 17(1):35-40.
Römer, P., P.D.S., Caligari, M.A., Rahim, C., Huyghe, A., Hardy, J., Neves-Martins, E. and Sawicka-Sienkiewicz. 1999. Breeding perspectives of Lupinus mutabilis in the Middle Europe. In: Hill GD, editor. Proceedings of the of the $8^{\text {th }}$ International Lupin Conference Towards the $21^{\text {st }}$ Century, 11-16 May 1996; Asilomar, California, USA: North American Lupin Associattion on behalf of the International Lupin Association, pp.353-356.

Sawicka-Sienkiewicz, E., R., Galek, J.C. Clements and J. Wilson. 2008. Difficulties with interspecific hybridisation in the genus Lupinus. In: Palta JA, Berger JD, Editors of the $12^{\text {th }}$ International Lupin Conference Lupin for Health and Wealth, 14-18 September 2008; Fremantle, Western Australia: International Lupin Association, pp.135-142

Sipsas, S. 2008. Lupin products - concepts and reality. In: Palta JA, Berger JD, editors. Proceedings of the $12^{\text {th }}$ International Lupin Conference Lupin for Health and Wealth, 14-18 September 2008; Fremantle, Western Australia: International Lupin Association, pp.506 - 513.

Sweetingham., M. and R., Kingwell. 2008. Lupin - reflections and future possibilities. In: Palta JA, Berger JD, editors. Proceedings of the $12^{\text {th }}$ International Lupin Conference Lupin for Health and Wealth, 14-18 September 2008; Fremantle, Western Australia: International Lupin Association, pp.514- 525 . 